\title{
The Effect of Position of Heated Rod in Tube Banks on the Heat Transfer Coefficient
}

\author{
Ehsan Fadhil Abbas ${ }^{1}$ \\ ${ }^{1}$ Department of Refrigeration and Air Conditioning, Kirkuk Technical College, Foundation of Technical \\ Education, Iraq \\ Correspondence: Ehsan Fadhil Abbas, Department of Refrigeration and Air Conditioning, Kirkuk Technical \\ College, Foundation of Technical Education, Iraq. Tel: 964-770-610-2864. E-mail: ehsanfadhil@gmail.com
}

Received: February 16, 2015 Accepted: March 7, 2015 Online Published: March 30, 2015

doi:10.5539/mer.v5n1p24

URL: http://dx.doi.org/10.5539/mer.v5n1p24

\begin{abstract}
Heat transfer in flow across a bank of tubes is of a particular importance in the design of heat exchangers. Heat exchangers are used in numerous services and industrial applications. Experimental studies were performed, carried out in cross-flow tube banks. They contain copper heated rod and 17 Aluminum rods arranged in the form of staggered and at arrange of Reynolds number 2700 to 21530 . The experimental results indicated that the location of the heated rod in the work section affects the value of heat transfer coefficient thus this value is increased when the heated rod location changes both the $y$ and $x$-directions. The experimental data revealed good agreement with Zukauskas correlation in four columns.
\end{abstract}

Keywords: tube banks, cross-flow heat exchanger, convection from tube banks, heat transfer coefficient

\section{Nomenclature}

A : Surface area.

$\mathrm{A}_{\mathrm{e}}$ : Effective surface area.

$m^{2}$

$\mathrm{C}:$ Column.

$C_{p}$ : Specific heat capacity of copper.

$\mathrm{J} / \mathrm{kg} \cdot{ }^{\circ} \mathrm{C}$

$\mathrm{d}$ : Diameter.

$m$

$\mathrm{h}$ : Heat transfer coefficient.

$W / m^{2} \cdot{ }^{o} \mathrm{C}$

$\mathrm{k}$ : Thermal conductivity of copper

$\mathrm{W} / \mathrm{m} \cdot{ }^{\circ} \mathrm{C}$

$\mathrm{k}_{\mathrm{a}}$ : Thermal conductivity of air.

$\mathrm{W} / \mathrm{m} .{ }^{\circ} \mathrm{C}$

$\mathrm{m}$ : Mass of copper.

$\mathrm{kg}$

$\mathrm{Nu}_{\mathrm{d}}$ : Nusselt number based on rod diameter.

Pr : Prandtl number.

$\mathrm{Re}_{\mathrm{d}}$ : Reynolds number based on rod diameter.

$\mathrm{S}_{\mathrm{D}}$ : Diagonal pitch.

$m$

$\mathrm{S}_{\mathrm{L}}$ : Longitudinal distance between two consecutive tubes $m$

$\mathrm{S}_{\mathrm{T}}$ : Transverse distance between two consecutive tubes $m$

$\mathrm{T}:$ Temperature of the surface at any time. $\quad{ }^{\circ} \mathrm{C}$

$\mathrm{T}_{\infty}$ : Ambient temperature. $\quad{ }^{\circ} \mathrm{C}$

$\mathrm{T}_{\mathrm{o}}$ : Initial temperature. $\quad{ }^{\circ} \mathrm{C}$

\section{Introduction}

A tube bundle is one of the simplest but more effective geometries in heat transfer applications. The bundle consists of a multiple cylindrical bars or circular tubes. The bundle tube heat exchangers are found in numerous industrial applications, ranging from low- tech applications such as domestic water heaters to high-tech 
applications such as hypersonic jet engine. Their size similarly varies extensively, from massive power plant boilers to extremely small chip coolers. In general, for convenience, tube bundles are installed such that the shell-side stream flows perpendicularly to the tubes (Jeong et al., 2011). Tube banks are usually arranged in-line or in staggered manner and are characterized by the dimensionless transverse, longitudinal, and diagonal pitches. Typically, one fluid moves over the tubes, while the other fluid at a different temperature, passes through the tubes (Kan, Culhum, \& Yovanovich, 2006). Below is a brief summary of a number of researchers who experimentally, analytically and numerically have developed and determined the rate of heat transfer and flow structure around circular cylinder placed in a tube bank heat exchanger.

Brevoort \& Trifford (1942) have presented an experimental investigation of the details of the flow of fluids across tube banks. Information that clarifies the picture of the flow has been obtained by surveys of total dynamic and static pressure by visualization of flow through the use of titanium tetrachloride smoke. Martin \& Gnielinsk (2000) have discovered a new type of analogy between pressure drop and heat transfer, that may be used in chevron-type plate heat exchanger in packed bed, and tube bundles in cross-flow for both inline and staggered arrangements. The new method is to calculate heat and mass transfer from pressure drop in tube bundles with a single adjustable parameter of fraction of total pressure drop due to friction, which has been found to be 0.5 in all cases recommended especially for the staggered tube bundle. However this method in case of inline bundles gives slightly less accuracy than the older one in the law of Reynolds number range. Khan et al. (2006) proposed analytical method to investigate the heat transfer from tube banks in cross-flow under isothermal boundary conditions in both cases i.e in-line and staggered arrangements. The results showed that the models for in-line and staggered arrangements are applicable for use over a wide range of Reynolds and Prandtl numbers as well as longitudinal and transverse pitch ratios. Horvat, Leskovar, and Mavko (2006) compared heat transfer coefficient in tube bundle cross-flow heat exchanger for different tube shapes. Numerical analysis of heat transfer was performed for the heat exchanger segments with the cylindrical, the ellipsoidal and the wing-shaped tubes in the staggered arrangement. This comparative study showed that the wing-shaped which gives the best result based on these average values, drags the coefficient and Stanton number with respect of Reynolds number. Takemoto, Kawanishi, and Mizushima (2010) studied heat transfer in the flow through a bundle of heated tubes and transitions of the flow and discuss the effect of transition of flow upon the heat transfer characteristics numerically. The results of this study indicated that the physical quantities such as the Nusselt number and pressure exhibit discontinued jumps with continuous change in the Reynolds number. Ji et al (2011) presented and investigated the effects of the evaluation method on the average heat transfer coefficient for a mini-channel tube bundle. The study was performed with a tube diameter of $1.5 \mathrm{~mm}$ and shell side Reynolds number of $3000 \leq R e \leq 7000$. The average convection heat transfer coefficient can be estimated by a surface temperature method based on Newton's cooling law and the LMTD method. The result showed that the convection heat transfer coefficient by LMTD method was $22.6 \%$ smaller than that yielded by the surface temperature method. Mehrabian (2007) evaluated experimentally the value of heat transferred coefficient directly between a cylindrical copper element and the air flowing past it in specially designed test rig. The comparison of experimental results with predications of a standard correlation shows that the two sets of data are in close agreement; also the experimental data gives a linear relationship between upstream velocity and pressure drop across the tube bank. Abd (2012) studied the effect of the external shape of a heated rod (cylindrical, square and triangular) on the convection heat transfer coefficient when the body is subjected to free or forced convection heat transfer by cross flow air stream. The results were in good agreement with the standard correlation.

The objective of this paper is to study experimentally the effect of heated rode position on the value of heat transfer coefficient in cross flow heat exchanger in a range of Reynolds number 2700 to 21530 and compare the test results with two standard correlation methods.

\section{Equipment Description}

The TE93 cross-flow heat exchanger apparatus, manufactured by (TecQuipment) was used in this study. A constant speed $(2500 \mathrm{rpm})$ electric centrifugal fan $(1 \mathrm{hp})$ draws ambient air through duct having a square cross section of $12.5 * 12.5 \mathrm{~cm}$ (the working section) is transparent and includes holes for insertion of aluminum rods arranged as staggered form at right angle to the airflow. The air flow rate over rods regulated by a throttling valve installed to the discharge end. The base of the working section consists of two static pressure tapping used to measure the pressure drop across the rods. The air velocity measure directly by pitot tube as shown in Figure (1). The components and all dimensions of work section are shown in Figure 2. A special heated rod is placed at a selected position in the working section, and it is made of several parts; the main part heating rod is a pure copper, machined and drilled to allow for insertion of a thermocouple, and the two ends of the rod are closed by 
Teflon. The Teflon ends are for thermal insulation. The schematic diagram of the heated rod shown in Figure 3. And technical specification of heating rod a shown in Table 1. The apparatus consists of a control and instrumentation unit, which is included the electrical control elements such as main switch and on/off control for the electric fan and heater compartment for heated rod. Also included digital measuring devices for each of the rod surface temperature, inlet and outlet air temperatures measured by thermocouples type K, pressure drop across working section which was measured by tube adapters fit into the ends of the pipe work. All collected data were shown directly through a small display. This unit can be connected to PC by VDAS-B hardware to record all required data instantaneously during a test.
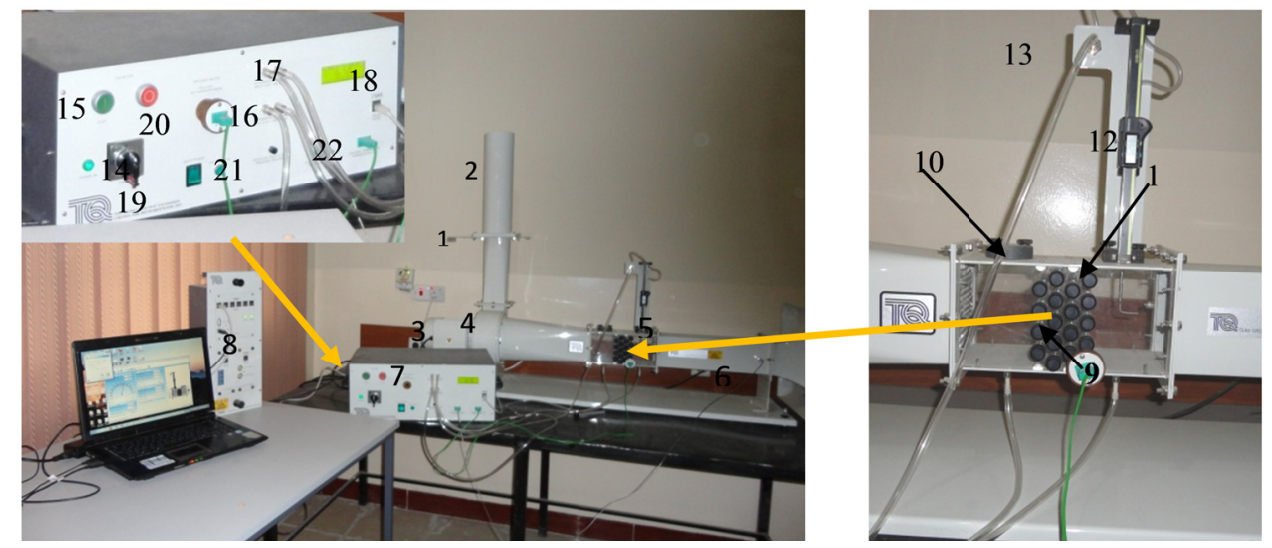

Figure 1.The experimental apparatus

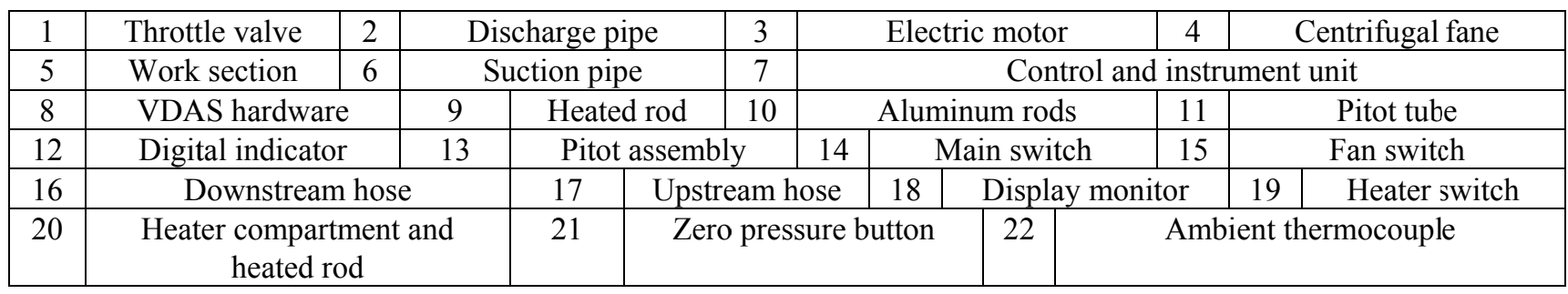

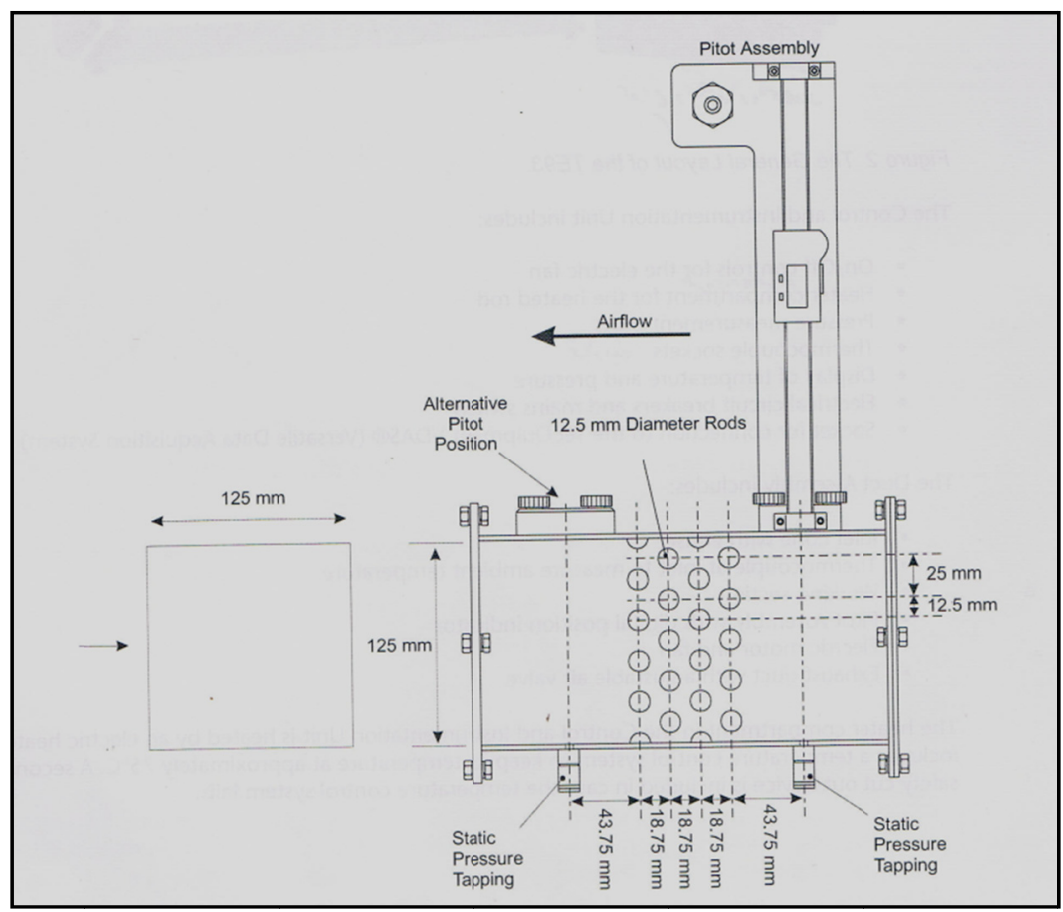

Figure 2. Schematic diagram of the working section (TE93 Cross-Flow Heat Exchanger, User Guide 2009) 


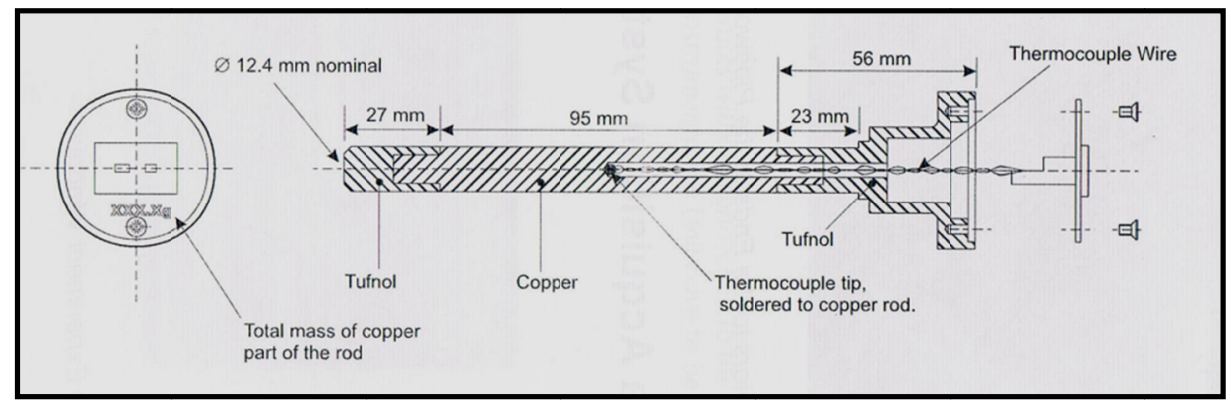

Figure 3. Schematic diagram of the heated rod (TE93 Cross-Flow Heat Exchanger, User Guide 2009)

Table 1. Specification of heated rod (TE93 Cross-Flow Heat Exchanger, User Guide 2009)

\begin{tabular}{ll}
\hline Item & Specification \\
\hline Material & Copper \\
Mass & $152 \mathrm{~g}$ \\
Diameter & $0.0124 \mathrm{~m}$ \\
Length & $0.095 \mathrm{~m}$ \\
Effective Length & $0.1034 \mathrm{~m}$ \\
Surface area & $0.0037 \mathrm{~m}^{2}$ \\
Effective Area & $0.00403 \mathrm{~m}^{2}$ \\
Specific Heat capacity & $380 \mathrm{~J} / \mathrm{kg}^{\circ} \mathrm{C}$ \\
\hline
\end{tabular}

\section{Experimental Procedure}

The experimental procedure in the present study was developed to obtain the value of Nusselt number under various air flow rate regulated by throttling valve. Before starting the experimental work all aluminum rods fit into the working section, except the hole that was allocated for heated rod. The pitot assembly is in the upstream position, adjusted so that its probe points upstream, in the middle of the working section and then connected to the socket of the differential pressure input on the control and instrumentation unit. After these procedures, the test rig becomes ready to proceed with the experiment as follows:-

a. The control and instrumentation unit was set up and the heated rod is inserted into heater compartment, and heated to a maximum value of about $75^{\circ} \mathrm{C}$.

b. The throttle valve was open fully $(100 \%)$.

c. Heater rod was removed after it reached to set temperature and fit it into position C1R1.

d. The fan was switched on, while the software stared up to record required data every ten seconds until the surface temperature of heated rod reached the ambient temperature

e. The experimental procedure (a to d) was repeated with throttle valve open at $90 \%, 80 \%, 70 \%, 60 \%, 50 \%$, $40 \%, 30 \%, 20 \%$, and $10 \%$.

f. The experiment was repeated for different location of heated rod in each of the other rows in the first column (C1R2, C1R3, C1R4, and C1R5), and same procedure repeated in other three columns sequentially.

\section{Computational Method}

a) Assumptions

- All heat generated in the heated rod is transferred to the surrounding by convection.

- Heat transferred by radiation is neglected.

- Temperature variations within the mass can be neglected in comparison with the temperature difference between the mass and the surrounding fluid and surface-convection resistance, is large as compared with the internal-conduction resistance (Lumped-capacity system). Such analysis may be expected to yield reasonable estimates when the following condition is met (Holman, 1997):

$$
\frac{h(V / A)}{k}<0.1
$$


b) Problem Formulation

Energy balance:

Change of internal energy of the solid= Net heat transfer from heated rod (Copper rod) to the air stream

$$
\rho C_{p} V \frac{d T}{d \tau}=-h A\left(T-T_{\infty}\right)
$$

When $\boldsymbol{T}$ is greater than $T_{\infty}$, the mass is losing heat to the surroundings. Thus, the rate of addition is the negative of the heat loss rate.

$$
\text { Let } \theta=T-T_{\infty}
$$

Differentiating the Equation 3, the equation becomes:

$$
d \theta=d T
$$

Substitute Equations 3 and 4 into the Equation 2, we have

$$
\rho C_{p} V \frac{d \theta}{d \tau}=-h A \theta
$$

Rearrange Equation 5

$$
\frac{d \theta}{\theta}=-\frac{h A}{\rho C_{p} V} \cdot d \tau
$$

Since this is a first-order differential equation, when we integrate it, there will be an arbitrary constant in the solution. To evaluate it, we'll need an initial condition on the temperature of the mass $\left(T_{o}\right)$.

At $\tau=0 \quad \theta=\theta_{o}$

By integrating both sides of Equation 6

$$
\int_{\theta_{o}}^{\theta} \frac{d \theta}{\theta}=-\frac{h A}{\rho C_{p} V} \int_{0}^{\tau} d \tau
$$

The result yields:

$$
\begin{gathered}
\ln \left(\theta-\theta_{o}\right)=-\frac{h A}{\rho C_{p} V} \tau \\
\ln \left(\frac{\theta}{\theta_{o}}\right)=-\frac{h A}{\rho C_{p} V} \tau \\
\ln \left(\frac{T-T_{\infty}}{T_{o}-T_{\infty}}\right)=-\frac{h A}{\rho C_{p} V} \tau
\end{gathered}
$$

$A$ is replaced into $A_{1}$ because the effective length of the heater rod is actually slightly longer than the $95 \mathrm{~mm}$ length exposed copper part. The Teflon ends are not perfect insulator and conduct a small amount of heat. This gives a larger effective length. Test on lengths of solid copper rod of the diameter has shown that the heated rod has the same properties as a solid rod that is $8.4 \mathrm{~mm}$ longer. This gives a nominal effective length of $103.4 \mathrm{~mm}$ (TE93 Cross-Flow Heat Exchanger, User Guide 2009)

$$
\ln \left(\frac{T-T_{\infty}}{T_{o}-T_{\infty}}\right)=-\frac{h A_{e}}{\rho C_{p} V} \tau
$$

Equation 11, giving a chart of time against temperature should yield a straight line of slope M,

$$
M=-\frac{h A_{e}}{\rho C_{p} V}
$$


Since the value of heat transfer coefficient $\boldsymbol{h}$ can be found from Equation 12, as other factors are known. Where the value of $\boldsymbol{h}$ can be found from

$$
h=-\frac{m c_{p}}{A_{e}} M
$$

where

$$
m=\rho V
$$

\section{Sample of Calculation}

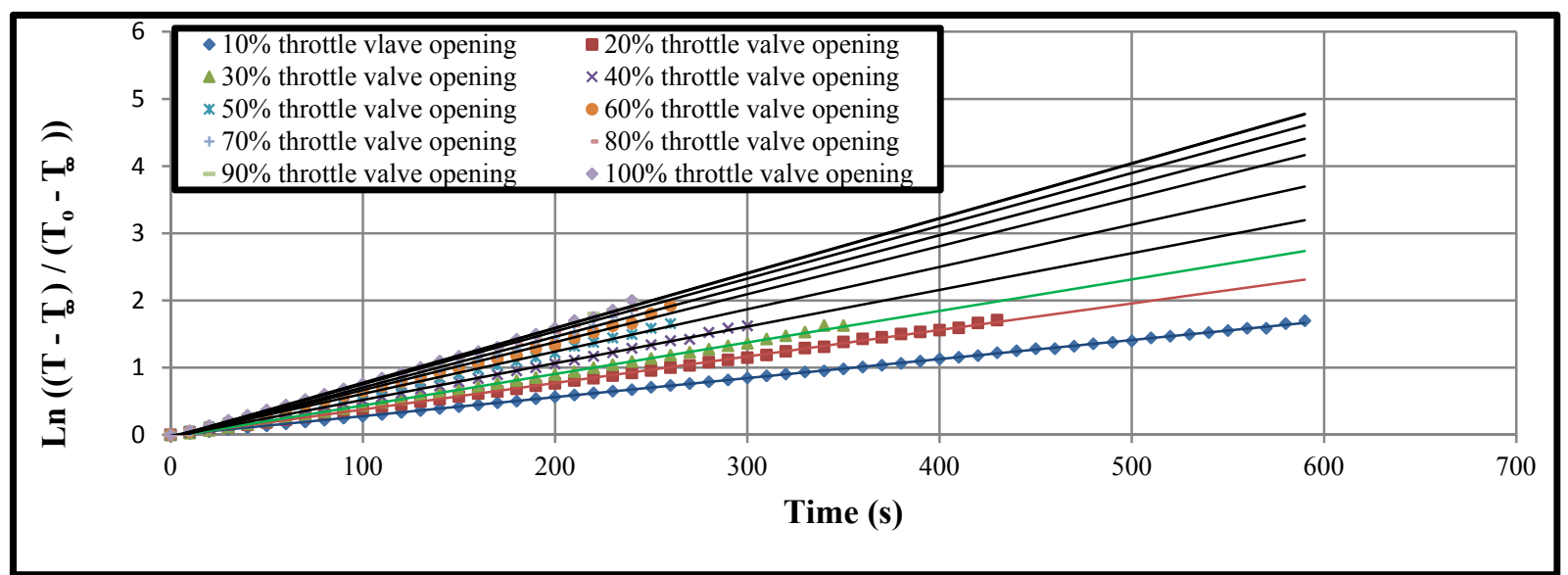

Figure 4. Relationship between $\ln \frac{T-T_{\infty}}{T_{o}-T_{\infty}}$ and time for different air flow rate

From the data recorded according to the time variation by VDAS-B unit, which were air stream velocity, air temperature, surface temperature of heated rod, upstream and downstream pressure. Below is the calculation of C1R1 of location of heated rod in work section. The value of heat transfer coefficient calculated from eq.(13), and the value of $\mathrm{M}$ for each flow rate of air can be obtained from Figure (4), and it is equal to the slope of straight line. Table (2) shows the value of $M$ in each percentage of throttle valve opening, coefficient of heat transfer (h) and Nusselt number by using the following relation

$$
\mathrm{Nu}=\frac{\mathrm{h} * \mathrm{~d}}{\mathrm{k}}
$$

Table 2. Sample calculation for C1R1

\begin{tabular}{ccccc}
\hline Throttle valve opening & $\mathrm{Re}_{\mathrm{d}}$ & $\mathrm{M}$ & $\mathrm{h} \mathrm{W} / \mathrm{m}^{2} .{ }^{\circ} \mathrm{C}$ & $\mathrm{Nu}$ \\
\hline $10 \%$ & 2691.21 & 0.002815 & 40.24134 & 18.27812 \\
$20 \%$ & 5382.419 & 0.003869 & 55.31639 & 25.12539 \\
$30 \%$ & 8073.629 & 0.004514 & 64.53685 & 29.31344 \\
$40 \%$ & 9541.695 & 0.005286 & 75.57952 & 34.32916 \\
$50 \%$ & 12110.44 & 0.006151 & 87.94251 & 39.94458 \\
$60 \%$ & 14801.65 & 0.006772 & 96.822 & 43.97776 \\
$70 \%$ & 17492.86 & 0.007131 & 101.9511 & 46.30745 \\
$80 \%$ & 18838.47 & 0.007587 & 108.4712 & 49.26896 \\
$90 \%$ & 20184.07 & 0.00775 & 110.7961 & 50.32498 \\
$100 \%$ & 21529.68 & 0.007828 & 111.9233 & 50.83697 \\
\hline
\end{tabular}


Table 3. Properties of air based on film temperature (Holman, 1997)

\begin{tabular}{ll}
\hline Properties of air & Value \\
\hline Density $\rho_{\mathrm{a}}$ & $1.0877 \mathrm{~kg} / \mathrm{m}^{3}$ \\
Thermal conductivity $k_{a}$ & $0.028135 \mathrm{~W} / \mathrm{m} .{ }^{\circ} \mathrm{C}$ \\
Viscosity $\mu_{\mathrm{a}}$ & $1.9606 \times 10^{-5} \mathrm{~kg} / \mathrm{m} . \mathrm{s}$ \\
Specific heat capacity $C_{p a}$ & $1.00735 \mathrm{~kJ} / \mathrm{kg} .{ }^{\circ} \mathrm{C}$ \\
\hline
\end{tabular}

Table 4. The minimum and maximum values of $\mathrm{Nu}$ for each row in four columns

\begin{tabular}{lllllllllll}
\hline Column & \multicolumn{2}{c}{ Row1 } & \multicolumn{2}{c}{ Row2 } & \multicolumn{2}{c}{ Row3 } & \multicolumn{2}{c}{ Row4 } & \multicolumn{2}{c}{ Row5 } \\
\cline { 2 - 11 } 1 & Min. & Max. & Min. & Max. & Min. & Max. & Min. & Max. & Min. & Max. \\
2 & 25 & 83 & 25.4 & 85.9 & 26.9 & 89.4 & 28.6 & 96.6 & 30.9 & 104.5 \\
2 & 28.7 & 102.6 & 29.9 & 106.7 & 30.9 & 110.2 & 32.1 & 114 & & \\
3 & 29 & 103 & 31 & 110 & 32.3 & 115.3 & 35.7 & 127.4 & 36.5 & 130.4 \\
4 & 33.4 & 116.8 & 34.4 & 119.6 & 36.5 & 127.1 & 40.5 & 141 & & \\
\hline
\end{tabular}

\section{Results and Discussion}

1) Effect of heated rod location on Nusselt number

A set of experimental data were obtained from changing the position of heated rod through C1R1 to C4R4 and within a Reynolds number range of $2700-21530$ for each location. Data obtained from all tests in this research proved that the value of Nusselt number increased when heated rod was moved in two directions such as in $y$ and $\mathrm{x}$-directions in work section. And also the value of Nusselt number increased when increasing Reynolds number. Table 4 shows as the maximum and minimum value of Nusselt number for each row in the four presented columns. This fact can be observed through Figures 5 to 8, which describe a relationship between $\mathrm{Nu}$ with Re in each row from column 1 to column 4 respectively.

2) Comparison of the result of present study with standard correlations(Yovanovich, Kan, $\mid \&$ Culhum, 2005) The result of experimental procedures was compared with two standard correlations of (Zukauskas and Grimison) for staggered arrangement tube bank in cross flow (. The mathematical expression of Zukauskas, 1972 correlation is shown as follows:

$$
\mathrm{Nu}_{\mathrm{d}}=\mathrm{FCRe}_{\mathrm{d}}^{\mathrm{n}} \operatorname{Pr}^{\mathrm{m}}
$$

Where this correlation works for $N_{L} \leq 16$, and $10^{3} \leq R e_{d} \leq 2 \times 10^{5} . N_{L}$ is number of columns, $F$ is correction factor. The constants $C, n$ and $m$ vary depending on the Reynolds number and tube bank geometry, as shown in appendix.

The mathematical expression of Grimison is shown below:

$$
\mathrm{Nu}_{\mathrm{d}}=\mathrm{FCRe}_{\mathrm{d}}^{\mathrm{n}} \operatorname{Pr}^{1 / 3}
$$

This correlation is valid for $N_{L} \leq 16$ where $F$ is correction factor and $(C, n)$ are constants that depend on tube bank geometry, as shown in appendix.

In the present study the average value of Nusselt number in each column can be calculated from the following relation:

$$
\overline{\mathrm{Nu}}=\frac{\sum_{\mathrm{i}=1}^{\mathrm{i}=\mathrm{n}} \mathrm{Nu}_{\mathrm{i}}}{\mathrm{n}}
$$

where $n$ is the number of rows in each column.

The values of average Nusselt number calculated from these correlations are compared with the results of the present study for Reynolds number ranging from 2700 to 21530 as shown in Figures 9, 10, 11 and 12 for first column to fourth column respectively. The results of the four columns in present study are in close agreement with Zukauskas correlation. 


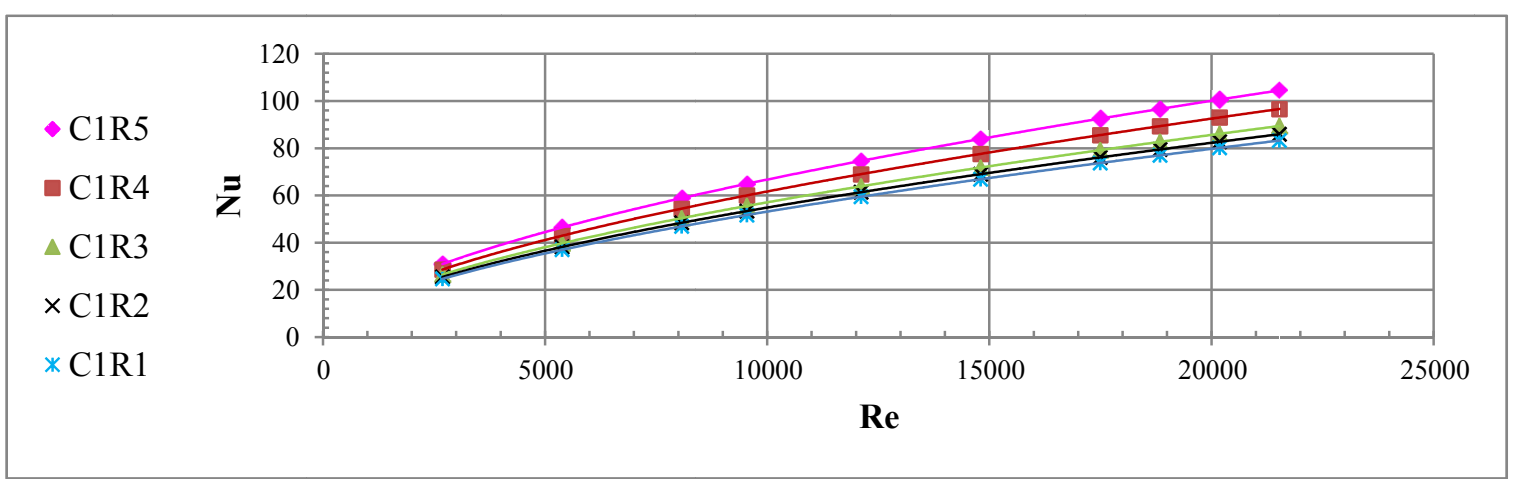

Figure 5. The effect of heated rod position on the value of $\mathrm{Nu}$ with respect of Re in column 1

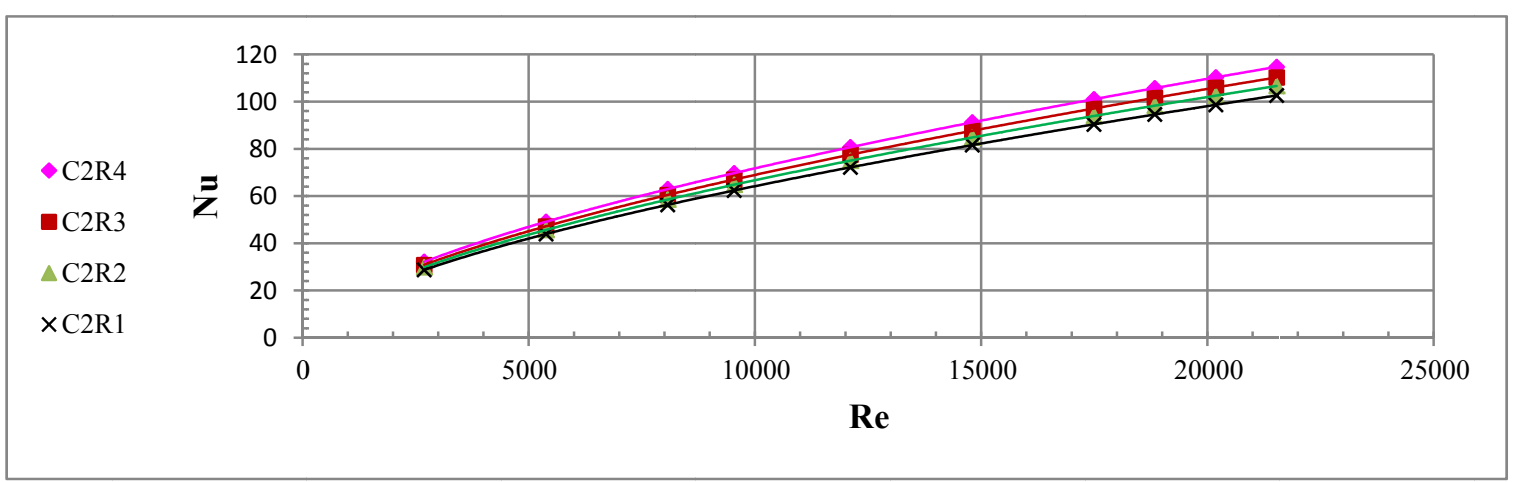

Figure 6. The effect of heated rod position on the value of $\mathrm{Nu}$ with respect of $\mathrm{Re}$ in column 2

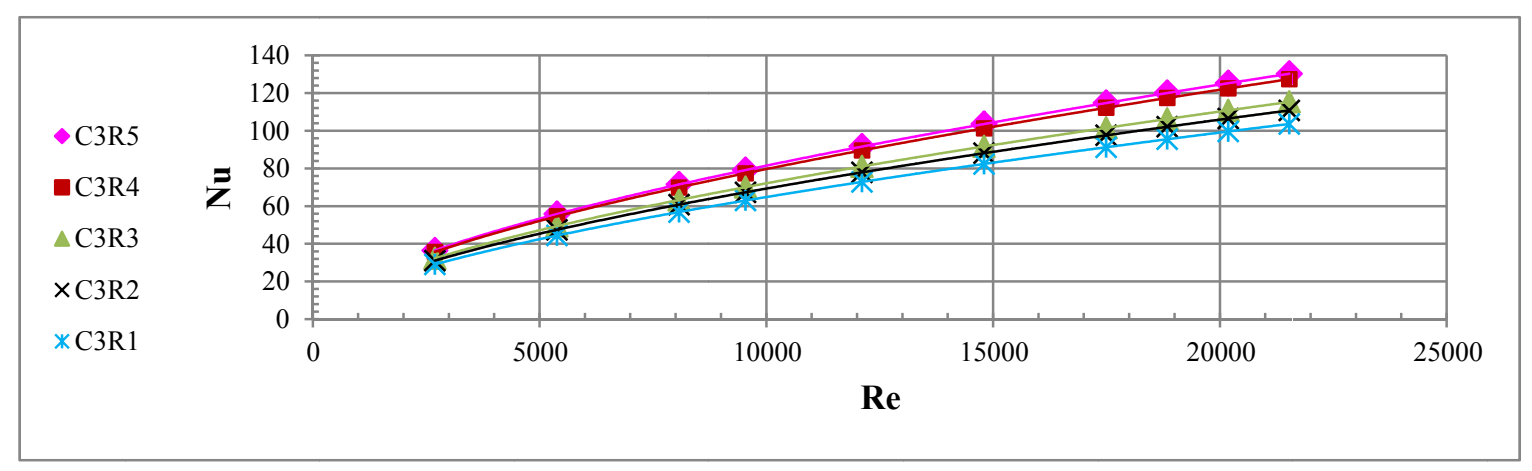

Figure 7. The effect of heated rod position on the value of $\mathrm{Nu}$ with respect of $\mathrm{Re}$ in column 3

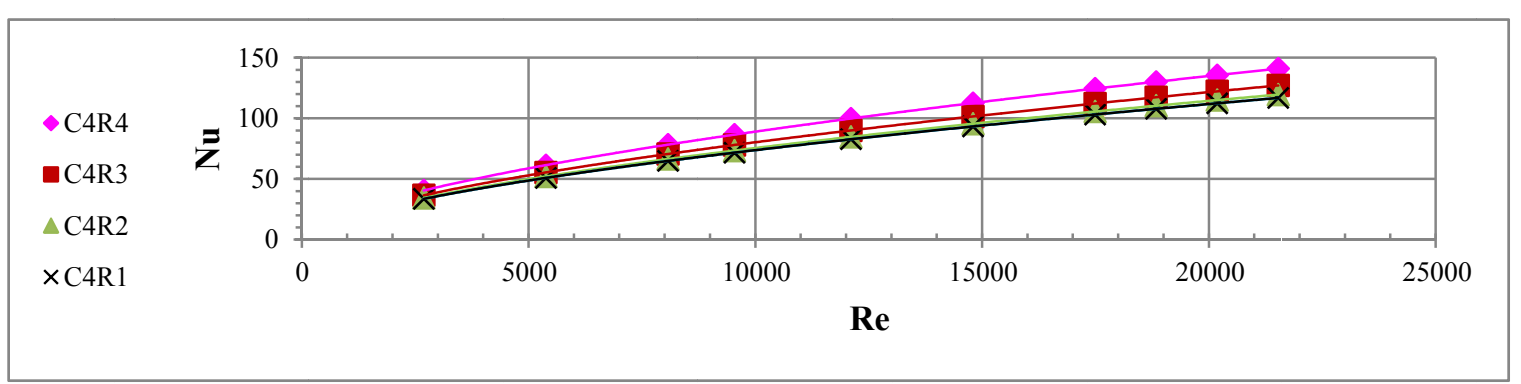

Figure 8 . The effect of heated rod position on the value of $\mathrm{Nu}$ with respect of Re in column 4 


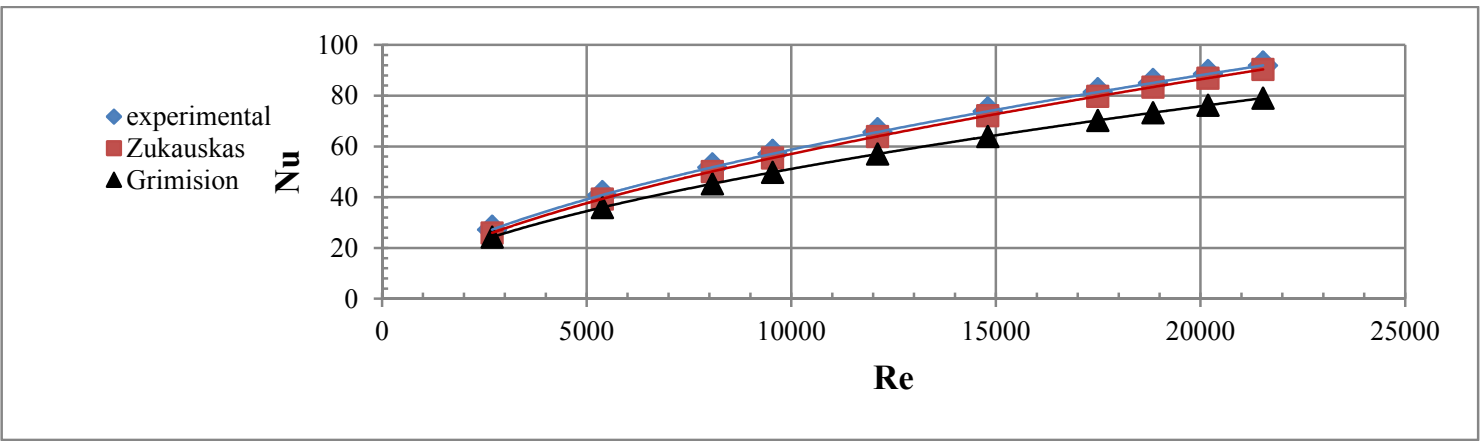

Figure 9. Comparison of experimental $\mathrm{Nu}$ and standard correlations for column1

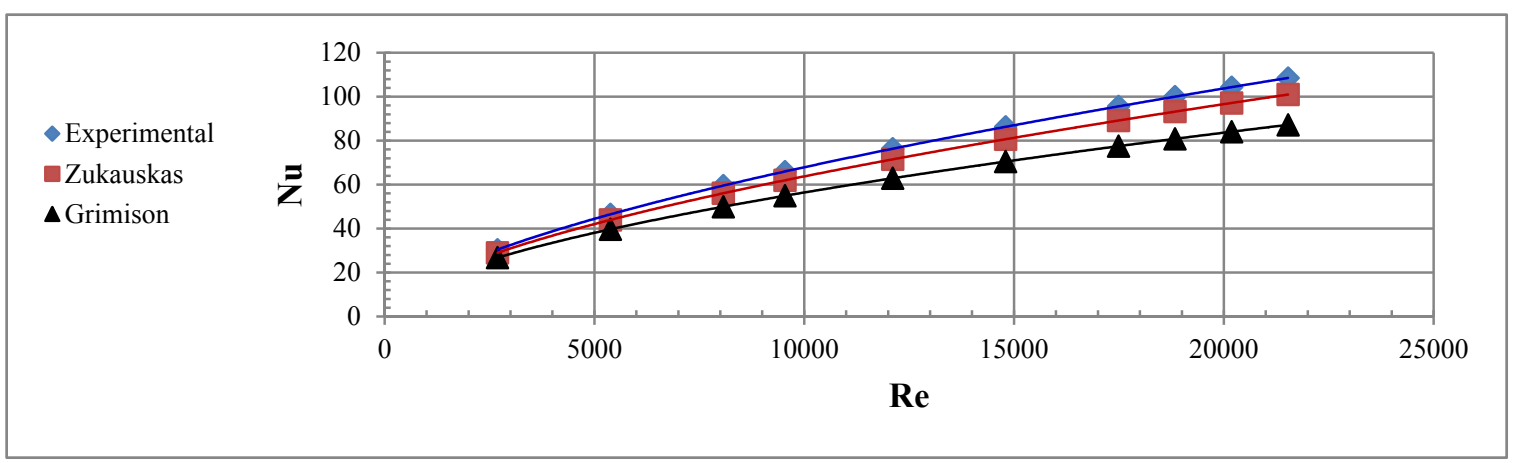

Figure 10. Comparison of experimental $\mathrm{Nu}$ and standard correlations for column2

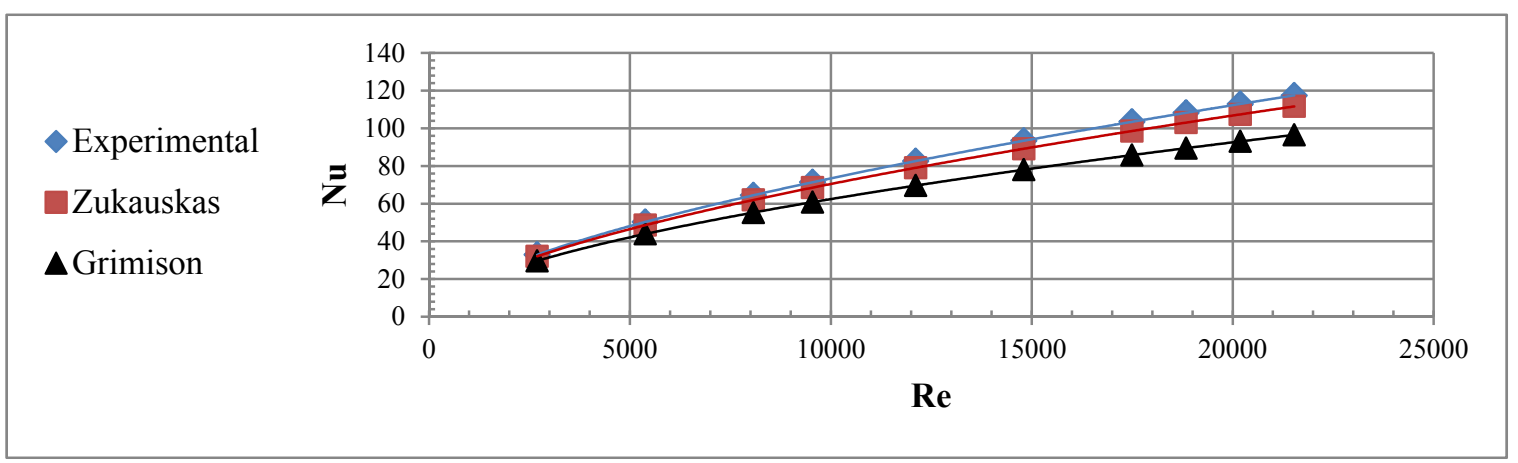

Figure 11. Comparison of experimental $\mathrm{Nu}$ and standard correlations for column3

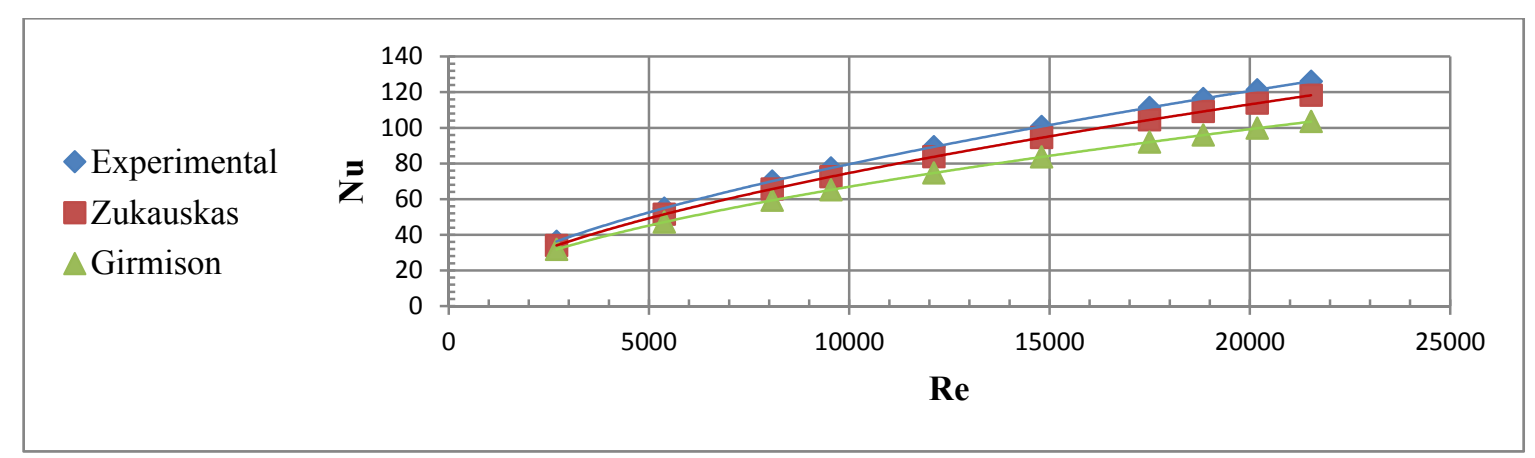

Figure 12. Comparison of experimental $\mathrm{Nu}$ and standard correlations for column4 


\section{Conclusion}

It is clear from the experimental results that the value of heat transfer coefficient increases when the location of heated rod is changed in $\mathrm{x}$ and $\mathrm{y}$-direction with respect of C1R1 in work section. Also this value increased with increasing Reynolds. The results of all relationships between Nusselt number and Reynolds number in the four columns showed a good agreement with Zukauska correlation.

\section{References}

Abd, S. H. (2012). Experimental Study on the Impact of External Geometrical Shape on Free and Force Convection Time Dependent Average Heat Transfer Coefficient during Cooling Process. Al-Khwarizmi Engineering Journal, 8(3), 74 - 89. Retrieved from http://repository.uobaghdad.edu.iq/ArticleShow. aspx?ID=1979

Brevoort, M. J., \& Tifford, A. N. (1942). An Experimental Investigation of Flow Across Tube Banks. National Advisory Committee for Aeronautics Wartime Report, L-232. Retrieved from http://ntrs.nasa.gov/archive/ nasa/ casi.ntrs.nasa.gov/19930093156.pdf

Holman, P. H. (1997). Heat Transfer (8th ed.). New York, NY: McGraw-Hill.

Horvat, A., Leskovar, M., \& Mavko, B. (2006). Comparison of Heat Transfer Conditions in Tube Bundle Cross-Flow for Different Tube Shape, International Journal of Heat and Mass Transfer, 49(5-6), 10271038. Retrieved from http://www.sciencedirect.com/science/article/pii/S001793100500668X

Jeong, J. H., Nam, K. W., Min, J. K., Kim, K. S., \& Ha, M. Y. (2011). The Effects of the Evaluation Method on theAverage Heat Transfer Coefficient for Mini-Channel Tube Bundle. International Journal of Heat and Mass Transfer, 54(25-26), 5481-5490. Retrieved from http://www.sciencedirect.com/science/article/pii/ S0017931011004297

Khan, W. A., Culham, J. R., \& Yovanovich M. M. (2006). Convection Heat Transfer from Tube Banks in Cross-Flow, Analytical approach, International Journal of Heat and Mass Transfer, 49(25-26), 4831-4838. Revised from http://www.sciencedirect.com/science/article/pii/S0017931006003796

Khan, W. A., Culham, J. R., \& Yovanovich M. M.(2006). Analytical Model Force Convection Heat Transfer from Tube Banks. Thermophysics and Heat Transfer, 20(4), 720-727. http://arc.aiaa.org/doi/abs/10.2514/ 1.15453

Martin, H., \& Gnielinsk, V. (2000). Calculation of Heat Transfer from Pressure Drop in Tube Bundles. Paper presented at the third European Thermal Science Conference. Retrieved from http://digbib.ubka.unikarlsruhe.de/volltexte/documents/2579184

Mehrabian, M. A. (2007). Heat Transfer and Pressure Drop Characteristics of Cross low of Air Over Circular Tube in Isolation and/or in a Tube Bank. The Arabian Journal for Science and Engineering, 32(2B), 365-376. Retrieved from http://ajse.kfupm.edu.sa/articles/322b_p.14.pdf

Takemoto, Y., Kawanishi, K., \& Mizushima, J. (2010). Heat Transfer in the Flow Through a Bundle of Tubes and Transitions of the Flow. International Journal of Heat and Mass Transfer, 53(23-24), 5411-5419.

TE93 Cross-Flow Heat Exchanger, User Guide. (2009). TecQuipment Ltd, Nottingham NG102AN, UK.

Yovanovich, M. M., Khan, W. A., \& Culham, J. R. (2005). Convection Heat Transfer from Tube Banks in Cross Flow: Analytical Approach, $43^{\text {rd }}$ Aerospace Science Meeting and Exhibit, Reno, Nevada. Retrieved from http://www.mhtlab. uwaterloo.ca/pdf_presentations/aiaa0105-2.pdf

\section{Appendix}

Available Correlations (Tube Banks)

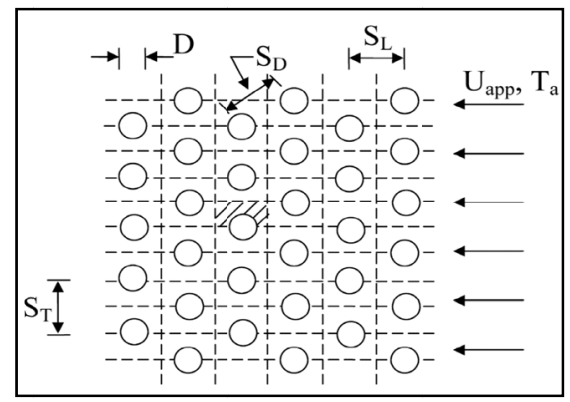


1) Zukauskas, 1972: $N u_{D}=F C R e_{D}^{n} \operatorname{Pr}^{m}$

\begin{tabular}{lcccc}
\hline Geometry & $\mathbf{C}$ & $\mathbf{n}$ & $\mathbf{m}$ & Conditions \\
\hline Staggered & 1.04 & 0.4 & 0.36 & $10 \leq R e_{\text {Dmax }} \leq 500$ \\
& & & $S_{T} / S_{L}<2$ \\
& $0.35\left(\mathrm{~S}_{\mathrm{T}} / \mathrm{S}_{\mathrm{L}}\right)$ & 0.6 & 0.36 & $10^{3} \leq R e_{\text {Dmax }} \leq 2 \times 10^{5}$ \\
& & & $S_{T} / S_{L}>2$ \\
& 0.4 & 0.6 & 0.36 & $10^{3} \leq R e_{\text {Dmax }} \leq 2 \times 10^{5}$ \\
& 0.022 & 0.84 & 0.36 & $R e_{\text {Dmax }} \leq 2 \times 10^{5}$ \\
\hline
\end{tabular}

$F=$ Correction factor for $N L \leq 16$

\begin{tabular}{cccccccccc}
\hline $\mathbf{N}_{\mathbf{L}}$ & $\mathbf{1}$ & $\mathbf{2}$ & $\mathbf{3}$ & $\mathbf{4}$ & $\mathbf{5}$ & $\mathbf{7}$ & $\mathbf{1 0}$ & $\mathbf{1 3}$ & $\mathbf{1 6}$ \\
\hline staggered & 0.64 & 0.76 & 0.84 & 0.89 & 0.93 & 0.96 & 0.98 & 0.99 & 1.00 \\
\hline
\end{tabular}

2) Grimision, 1937: $N u_{D}=F C \operatorname{Re}_{D}^{n} \operatorname{Pr}^{1 / 3}$

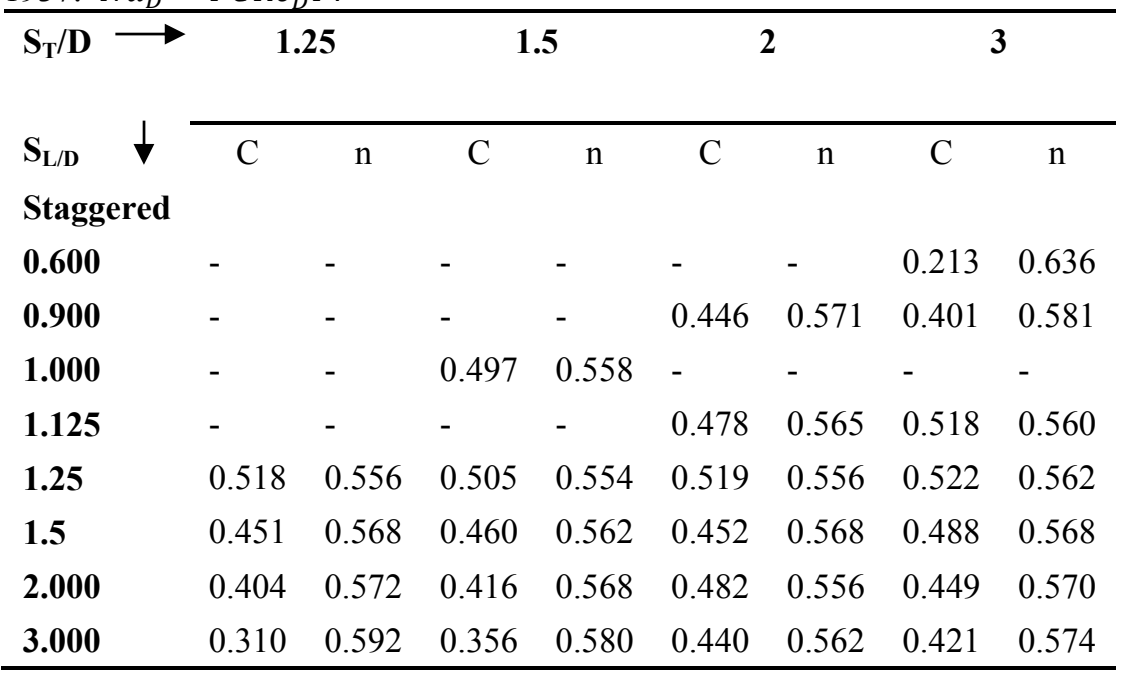

$F=$ Correction factor for $N L \leq 10$

\begin{tabular}{ccccccccccc}
\hline $\mathbf{N}_{\mathbf{L}}$ & $\mathbf{1}$ & $\mathbf{2}$ & $\mathbf{3}$ & $\mathbf{4}$ & $\mathbf{5}$ & $\mathbf{6}$ & $\mathbf{7}$ & $\mathbf{8}$ & $\mathbf{9}$ & $\mathbf{1 0}$ \\
\hline staggered & 0.68 & 0.75 & 0.83 & 0.89 & 0.92 & 0.95 & 0.97 & 0.98 & 0.99 & 1.00 \\
\hline
\end{tabular}

\section{Copyrights}

Copyright for this article is retained by the author(s), with first publication rights granted to the journal.

This is an open-access article distributed under the terms and conditions of the Creative Commons Attribution license (http://creativecommons.org/licenses/by/3.0/). 